\title{
Antioxidant and Antimicrobial Activities of Exopolysaccharides from Yoghurt Starter
}

\author{
Bachir Raho Ghalem \\ Process Engineering and Chemistry of Solutions Laboratory, Department of Biology, University of Mascara, Mascara, Algeria
}

\section{Email address:}

bachir_raho@yahoo.fr

\section{To cite this article:}

Bachir Raho Ghalem. Antioxidant and Antimicrobial Activities of Exopolysaccharides from Yoghurt Starter. Advances in Biochemistry. Vol. 5, No. 5, 2017, pp. 97-101. doi: 10.11648/j.ab.20170505.13

Received: May 30, 2017; Accepted: June 27, 2017; Published: October 18, 2017

\begin{abstract}
The in vitro antimicrobial and antioxidant activities of the exopolysaccharide (EPS) extracted from yoghurt starter were investigated. Antimicrobial activity tests were carried out using disc diffusion methods with Escherichia coli, Staphylococcus aureus and Streptococcus D, Proteus spp and the yeast of Candida albicans. The antioxidant properties were evaluated using the test of DPPH free radical trapping. The results show that the EPS has weak antimicrobial activity against the tested strains with inhibitions zones ranging from 9 to $13 \mathrm{~mm}$. EPS could reduce the free radical (DPPH) to diphenylpicrylhydrazine a yellow-colored at $24.25 \%$ showing antioxidant activity less than that of ascorbic acid which was $69.79 \%$.
\end{abstract}

Keywords: EPS, Yoghurt Starter, Antimicrobial, Antioxidant Activities

\section{Introduction}

Antimicrobial resistance is one of the world's most serious public health problems. Many of the microbes (bacteria, viruses, protozoa) that cause infectious disease no longer respond to common antimicrobial drugs. There is an urgent need to find new efficient antimicrobial drugs [1]. In other hand, It has been found that free radicals and other reactive oxygen species play a cardinal role in oxidative damage to cellular constituents which leads to cell injury and death. This has been associated with pathogenesis of various chronic disease, e.g. carcinomas, coronary heart disease, and many other hearth problems related to advancing age [2]. Therefore, there is a need to develop new and safe antioxidants from natural sources to minimize the oxidative damages in living cells. Many species of bacteria possess the ability to synthesize and excrete extracellular polysaccharides (exopolysaccharides, EPS) [3]. The bacterial exopolysaccharides are widely used in food, pharmaceutical and chemical industries as bioflocculants, bioabsorbents, drug delivery agents, etc [4]. Lactic acid bacteria (LAB) are able to produce exopolysaccharides (EPSs) in the surrounding medium as a slime or on the surface of bacterial cells to form a capsule [5]. Some of the EPSs produced by LAB may confer health benefits such as immunemodulatory, anti-tumor, anti-bio film and antioxidant activities
[6]. The aim of this study was to evaluate the in vitro antioxidant and antimicrobial properties of the exopolysaccharides extracted from yoghurt starter.

\section{Material and Methods}

\subsection{Yoghurt Starter}

Freeze dried mixed yoghurt culture (Lactobacillus delbrueckii subsp. bulgaricus and Streptococcus salivarius subsp. thermophilus) was obtained from GIPLAIT dairy unit of Tizi (Mascara).

\subsection{Inoculum Preparation}

The inoculum for the experiments was prepared by growing $2 \%$ of yoghurt starter strain in $50 \mathrm{~mL}$ flasks containing $25 \mathrm{~mL}$ of the sterilised standard medium BMM (basal minimal medium) [7]. The flask was incubated at $30^{\circ} \mathrm{C}$ for $24 \mathrm{~h}$.

\subsection{Extraction of Exopolysaccharides}

Exopolysaccharides were extracted according to the method of Zhang et al (2011) [8] with modifications. After incubation, the medium inoculated with the yoghurt starter was maintained at $100^{\circ} \mathrm{C}$ for $15 \mathrm{~min}$ and refrigerated at $4^{\circ} \mathrm{C}$ for $24 \mathrm{~h}$. After the refrigeration period, the samples were 
centrifuged at $9950 \mathrm{xg}$ for $30 \mathrm{~min}$ at $4^{\circ} \mathrm{C}$ and the supernatant containing the EPS were precipitated with 3 volumes of cold ethanol $95 \%$. The samples were stored at $4^{\circ} \mathrm{C}$ for $3 \mathrm{~h}$ then centrifuged at $8000 \mathrm{x} \mathrm{g}$ for $20 \mathrm{~min}$ at $4^{\circ} \mathrm{C}$. The precipitate was re-suspended by dialysis in distilled water for $24 \mathrm{~h}$, then dried using a Christ lyophilizer until a constant weight was observed. The lyophilized samples were dissolved again in trichloroacetic $10 \%$, centrifuged at $5000 \mathrm{rpm}$ for $15 \mathrm{~min}$, dialysed for 5 days and lyophilized.

\subsection{Micro-organisms}

The organisms used in the microbiological assays were obtained from Laboratory of Medical Analysis at Meslem Tayeb hospital in Mascara city. The antimicrobial activity was individually tested against a panel of microorganisms, including Escherichia coli, Staphylococcus aureus and Streptococcus D, Proteus spp and the yeast of Candida albicans. The organisms were identified by cellular, cultural and biochemical characteristics. Bacterial strains were cultured overnight at $37^{\circ} \mathrm{C}$ in Mueller Hinton broth. Yeast was cultured at $30^{\circ} \mathrm{C}$ in Sabouraud dextrose broth.

\subsection{Antimicrobial Screening}

The Exopolysaccharides were examined for their antimicrobial activity by agar disc diffusion method [9]. Briefly, each suspension of the tested microorganism $\left(1 \times 10^{6}\right.$ $\mathrm{CFU} / \mathrm{ml})$ was spread on the solid media plates. Filter paper discs ( $5 \mathrm{~mm}$ in diameter) were individually impregnated with $10 \mu \mathrm{l}$ of undiluted EPS $(0.12,0.25,0.5$, and $1 \mathrm{mg} / \mathrm{ml})$ and placed on the incubated plates. After $30 \mathrm{~min}$ at room temperature, the dishes were incubated at $37^{\circ} \mathrm{C}$ for $24 \mathrm{~h}$ (for bacteria strains) and $30^{\circ} \mathrm{C}$ for $48 \mathrm{~h}$ (for yeast). At the end of the incubation period the antimicrobial activity was evaluated by measuring the clear inhibition zones formed around the discs. The antibiotic Gentamycin was used as positive control.

\subsection{Antioxidant Activity}

DPPH-radical scavenging activity of the EPS and control was measured according to the method described by Younes et al. (2012) [10] with some changes. $50 \mu$ of various concentrations $(0.02-0.1 \mathrm{mg} / \mathrm{ml})$ of EPS was added to 1.950 $\mathrm{ml}$ of methanolic solution containing DPPH (1,1- Diphenyl2-picryhydrazyl) radicals (2.4 mg DPPH was dissolved in $100 \mathrm{ml}$ of methanol). The mixture was shaken vigorously and allowed standing for $30 \mathrm{~min}$; the absorbance of the resulting solution was measured at $517 \mathrm{~nm}$ with a spectrophotometer. Inhibition of free radical DPPH in percent (I\%) was calculated in following way:

$$
\mathrm{I} \%=100 \mathrm{x}\left(\mathrm{A}_{\text {Control }}-\mathrm{A}_{\text {Sample }}\right) \mathrm{A}_{\text {Control }}
$$

Ascorbic acid was used as a control.

\section{Results}

The values for the diameter of the growth inhibition zones of the EPS for the different micro-organisms tested in the present study are shown in Table below. There was no activity observed against all organisms by the concentration of EPS ranged between 0.12 and $0.5 \mathrm{mg} / \mathrm{ml}$. In contrary, at 1 $\mathrm{mg} / \mathrm{ml}$ all tested micro-organisms showed sensitivity to EPS but their efficiency in inhibition was varied from one microorganism to another. The diameter of inhibition zones ranged between 9 and $13 \mathrm{~mm}$. The large zone of inhibition was observed against $E$. coli, while the lowest was recorded against the yeast $C$. albicans. S. aureus and Streptococcus D presented the same susceptibility to the EPS (10mm). Interestingly, the EPS was more active against Gramnegative bacteria (E. coli and Proteus Sp) than Gram-positive bacteria (S. aureus and Streptococcus D) and all bacteria are more susceptible than the yeast.

Table 1. Antimicrobial activity (zone of inhibition, $\mathrm{mm}$ ) of Exopolysaccharides against clinical pathogens.

\begin{tabular}{|c|c|c|c|c|c|c|}
\hline & & \multicolumn{5}{|c|}{ Diameter of the zone inhibition in $\mathrm{mm}$} \\
\hline & & S.aureus & E.coli & Streptococcus D & C.albicans & Proteus. $s p$ \\
\hline \multirow{4}{*}{ [EPS] $\mathrm{mg} / \mathrm{ml}$} & 1 & 10 & 13 & 10 & 9 & 12 \\
\hline & 0,5 & - & - & - & - & - \\
\hline & 0,25 & - & - & - & - & - \\
\hline & 0,12 & - & - & - & - & - \\
\hline Gen & $10 \mu \mathrm{g}$ & 15 & 16 & 15 & 17 & 27 \\
\hline
\end{tabular}
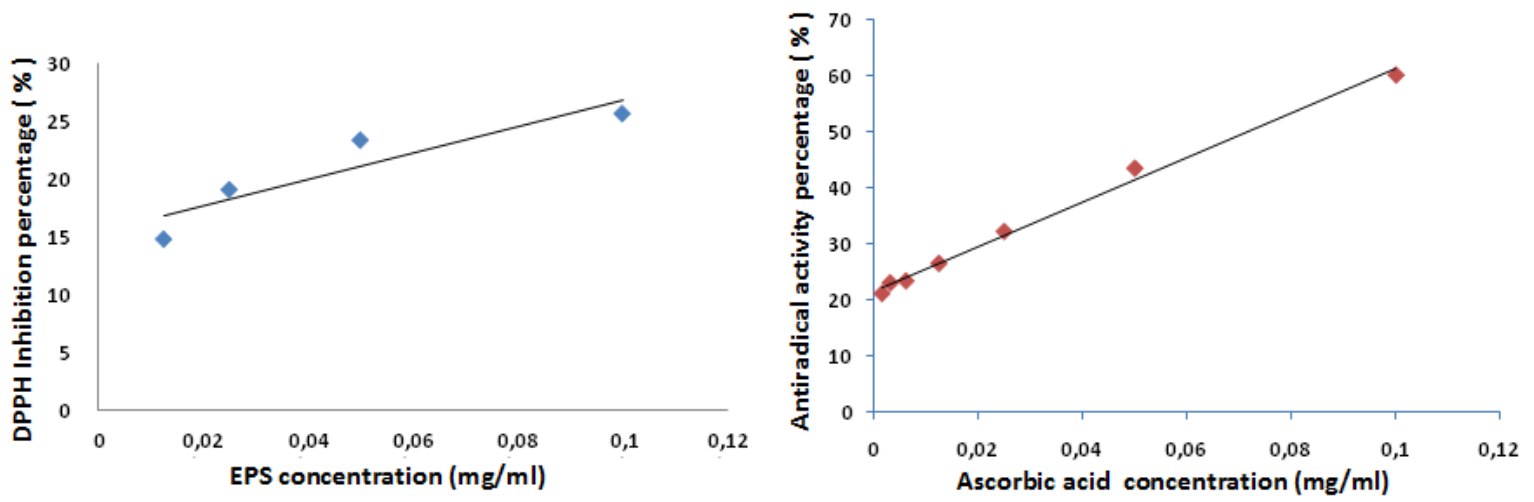

Figure 1. DPPH radical scavenging activity of standard antioxidant compound ascorbic acid and EPS from yoghurt starter. 
The percentage inhibition of DPPH radical scavenging capacity of EPS from yoghurt starter in comparison of ascorbic acid has been shown in Figure 1. The DPPH free radical scavenging activity of EPS and ascorbic acid was determined at concentration level ranged between $0.02 \mathrm{mg} / \mathrm{ml}$ and 0.1 $\mathrm{mg} / \mathrm{ml}$.

In this study, the EPS showed dose-dependent DPPH radical scavenging activity as did by ascorbic acid (standard). The scavenging activity directly increased with the promoting concentration. The maximum scavenging rate of EPS was $24.25 \%$ at $0.1 \mathrm{mg} / \mathrm{mL}$, whereas that of ascorbic acid was $69.79 \%$ at the same concentration.

\section{Discussions}

Many researchers have also shown that the Exopolysaccharides obtained from different source inhibited the growth of various microorganisms at different concentrations.

For example, Ezeronye et al. (2005) [1] investigated the antibacterial activities of crude polysaccharide of Pleurotus tuber-regium on some bacterial pathogens using the agar cup diffusion and disc diffusion methods. They found that ethanolic polysaccharide extracts of $P$ tuber-regium fruitbody showed mean inhibition zones of 19.33, 20.67, 23.00 and $26.67 \mathrm{~mm}$ on Enterococcus feacalis, Escherichia coli, Staphylococcus aureus and Salmonella typhi respectively. The Minimum Inhibitory Concentrations (MIC) determined by the agar cup diffusion techniques for the ethanolic polysaccharide were $6.25 \mathrm{mg} \mathrm{mL}^{-1}, 12.5 \mathrm{mg} \mathrm{mL}^{-1}$ and 12.5 $\mathrm{mg} \mathrm{mL} \mathrm{mL}^{-1}$ and $25 \mathrm{mg} \mathrm{mL}$ for Staphylococcus aureus, Escherichia coli, Salmonella typhi and Enterococcus feacalis respectively. Challouf et al. (2011) [11] also screened the antibacterial activities of different extracts of the EPS (Methanol, Hexane, Petroleum ether, Ethanol, Acetone, and Water) of Cyanobacterium Arthrospira platensis against a collection of Gram+/- bacteria by the paper disk agar diffusion method, the determination of Minimum Inhibitory Concentrations (MIC) and Minimum Bactericidal Concentrations (MBC). The methanol extract exhibited a more potent activity than the other organic extracts, whereas the aqueous extract was active against Staphylococcus epidermis (Gram+) and Salmonella typhimurium (Gram-). Recently, Majolagbe et al. (2013) [12] conducted in vivo studies on antibacterial properties of the crude exopolysaccharides of Lentinus subnudus injected intraperitoneally in aqueous solution $\left(20 \mathrm{mg} \mathrm{ml}^{-1}\right)$ into groups of Swiss albino rats infected with pathogenic strains of Escherichia coli and Pseudomonas aeruginosa. The prophylactic activities of the exopolysaccharides were monitored when administered 7 and 2 days before bacteria induction while therapeutic activities were monitored by administering the exopolysaccharides 1 hour after the bacterial induction. Nisha and Thangavel, (2014) [13] assessed the activity of EPS from Halomonassp (biofilm) against Escherichia coli, Klebsiella spp., Salmonella typhi and Staphylococcus sp, using the disc diffusion method. The EPS showed activity against the four microorganisms with diameter zone of inhibition ranged between 8 and $12 \mathrm{~mm}$. The same authors reported that Exopolysaccharide producing Micrococcus sp isolated from Arabian Sea had a weak antibacterial activity (zone of inhibition, $8-12 \mathrm{~mm}$ ) against the same tested clinical isolates in the previous work [14]. Li et al. (2014) [15] reported that exopolysaccharides isolated from Bifidobacterium bifidum WBIN03 and Lactobacillus plantarum R315 exhibited antimicrobial activities against tested pathogens such as Cronobacter sakazakii, Escherichia coli, Listeria monocytogenes, Staphyloccocus aureus, Candida albicans, Bacillus cereus, Salmonella typhimurium, and Shigella sonnei at $300 \mu \mathrm{g} / \mathrm{mL}$. In another Study, Li and Shah (2014) [16] reported that exopolysaccharides from Streptococcus thermophilus ASCC 1275 showed an inhibition zone of $9.8,14.5$ and $10.8 \mathrm{~mm}$ to E. coli ATCC 25922, S. aureus CMCC 26003 and L. monocytogenes CMCC 54001 respectively. Wang et al. (2015a) [17] also found that the exopolysaccharide (EPS) produced by Lactobacillus plantarum YW32 exhibited a concentrationdependent inhibitory effect on the formation of biofilms by several pathogenic bacteria, including Escherichia coli $\mathrm{O} 157$, Shigella flexneri CMCC (B), Staphylococcus aureus AC1 and Salmonella typhimurium S50333.

Similarly EPS from different microorganisms also showed DPPH free radical scavenging activity in a dose-dependent manner [18, 19, 20, 21].

Overproduction of free radicals can cause oxidative damage to biomolecules, (lipids, proteins, DNA), eventually leading to many chronic diseases such as atherosclerosis, cancer, diabetics, rheumatoid arthritis, post-ischemic perfusion injury, myocardial infarction, cardiovascular diseases, chronic inflammation, stroke and septic shock, aging and other degenerative diseases in humans [22]. EPSs have been proved to have antioxidant and free radical scavenging properties in several studies. Kishk and Al-Sayed. (2007) [23] observed the antioxidant and free radical scavenging activities of exopolysaccharide isolated from Rhizobium meliloti. A moderate antioxidant activity of methanol extract of exopolysaccharide from Cyanobacterium Arthrospira platensis using the Trolox Equivalent Antioxidant Activity assay was determined by Challouf et al. (2011) [11]. A strong scavenging ability of exopolysaccharide from Bifidobacterium bifidum WBIN03 and Lactobacillus plantarum R315 was observed against DPPH and superoxide radicals at high concentration [15]. The EPS produced by Lactobacillus plantarum YW32 at a dose of $5 \mathrm{mg} / \mathrm{ml}$ had strong scavenging abilities toward hydroxyl and superoxide radicals [17]. Water - soluble exopolysaccharides of Lactococcus lactis NCR112 isolated in Phyllanthus urinaria were capable of scavenging DPPH free radical [24].

In recent years, there has been an increasing interest in exploiting the EPS-producing lactic acid bacteria for their biological and therapeutic potential to be promising natural antioxidants and antimicrobials as well as food additives or 
functional food ingredients with both health and economical benefits [19]. Several studies have shown that microbial polysaccharides act as an effective antioxidant [ 25, 15, 17, 24], but very limited information is available on the antioxidant mechanisms of the exopolysaccharides action at molecular level $[6,26]$.

\section{Conclusion}

The EPS extracted from yoghurt starter was found to possess antioxidant and antimicrobial activities. The in vitro antioxidant study shows that EPS has the ability to scavenge DPPH free radicals. This study revealed also that the EPS exhibit antimicrobial property against the five tested organisms at a concentration of $1 \mathrm{mg} / \mathrm{ml}$. There is a need to conduct in vivo studies to ascertain the safety and acceptability of these products for their exploitation in food and pharmaceutical industries.

\section{References}

[1] Ezeronye OU, Okwujiako DAS and Onumajuru IA. 2005. Antibacterial effect of crude polysaccharide extracts from Sclerotium and fruitbody (sporophore) of Pleurotus tuberregium (Fried) Singer on some clinicales isolates. International Journal of molecular medecine and advance science. 1 (3): 202-205.

[2] Nantitanon W, Chowwanapoonpohn S and Okonogi S. 2007. Antioxidant and antimicrobial activities of Hyptis suaveolens Essential oil. Sci. Pharm. 75, 35-46.

[3] Castellane TCL, Lemos MVF, Lemos EGM. 2014. Evaluation of the biotechnological potential of Rhizobium tropici strains for exopolysaccharide production. Carbohydrate Polymers. 111: 191-197.

[4] Finore I, Di Donato P, Mastascusa V, Nicolaus B and Poli A. 2014. Fermentation Technologies for the Optimization of Marine Microbial Exopolysaccharide Production. Mar. Drugs, 12 (5), 3005-3024.

[5] Wang J, Zhao X, Tian Z, He C, Yang Y, Yang Z. 2015. Isolation and Characterization of ExopolysaccharideProducing Lactobacillus plantarum SKT109 from Tibet Kefir. Pol. J. Food Nutr. Sci., 65 (4): 269-279.

[6] Seo BJ, Bajpai VK, Rather IA and Park YH. 2015. Partially Purified Exopolysaccharide from Lactobacillus plantarum YML009 with Total Phenolic Content, Antioxidant and Free Radical Scavenging Efficacy. Indian Journal of Pharmaceutical Education and Research. 49 (4): 282-292.

[7] Morishita T., Deguchi Y., Yajima M., Sakurai T., Yura T., 1981, Multiple nutritional requirements of Lactobacilli: Genetic lesions affecting amino acid biosynthetic pathways, Journal of Bacteriology: 148 (1): 64-71.

[8] Zhang T, Zhang C, Li S, Zhang Y, Yang Z. (2011). Growth and exopolysaccharide production by Streptococcus thermophilus ST1 in skim milk. Brazilian Journal of Microbiology, 42: 1470-1478.

[9] Sarrazin SLF, Oliveira RB, Barata LES and Mourão RHV. (2012). Chemical composition and antimicrobial activity of the essential oil of Lippia grandis Schauer (Verbenaceae) from the western Amazon. Food Chemistry, 134: 1474-1478.

[10] Younes K, Merghache S, Djabou N, Merghache D, Muselli A, Tabti B and Costa J. 2012. Chemical composition, antibacterial and antioxidant activities of a new essential oil chemotype of Algerian Artemisia arborescens L. Afr. J. Pharm. Pharmacol. 6 (42): 2912-2921.

[11] Challouf R, Trabelsi L, Ben Dhieb R, El Abed O, Yahia A, Ghozzi K, Ben Ammar J, Omran H and Ben Ouada H. 2011. Evaluation of Cytotoxicity and Biological Activities in Extracellular Polysaccharides Released by Cyanobacterium Arthrospira platensis. Braz. Arch. Biol. Technol. 54 (4): 831-838.

[12] Majolagbe O. N., Oloke J. K., Adebayo E. A., Adewoyin A. G., Ayandele A. and Bamigboye C. O. 2013. Study on the Antibacterial Activity of Exopolysaccharides of Lentinus subnudus Using Swiss Albino Rats as Animal Model. American-Eurasian Journal of Scientific Research 8 (1): 47-52.

[13] Nisha. P and Thangavel M. (2014). Isolation and Characterization of Biofilm Producing Bacteria from Arabian Sea. Res. J. Recent. Sci. 3: 132-136.

[14] Nisha P and Thangavel M. (2014a). Isolation and characterization of exopolysaccharide from biofilm producing marine bacteria. World J Pharm Sci, 2 (8): 846-853.

[15] Li S, Huang R, Shah NP, Tao X, Xiong Y, Wei H. 2014. Antioxidant and antibacterial activities of exopolysaccharides from Bifidobacterium bifidum WBIN03 and Lactobacillus plantarum R315. J Dairy Sci. 97 (12): 7334-43.

[16] Li S, Shah NP. 2014. Antioxidant and antibacterial activities of sulphated polysaccharides from Pleurotus eryngii and Streptococcus thermophilus ASCC 1275. Food Chem. 165: 262-70.

[17] Wang J, Zhao X, Yang Y, Zhao A, Yang Z. 2015a. Characterization and bioactivities of an exopolysaccharide produced by Lactobacillus plantarum YW32. Int J Biol Macromol. 74: 119-26.

[18] Xu R, Shang N, Li P. 2011. In vitro and in vivo antioxidant activity of exopolysaccharide fractions from Bifidobacterium animalis RH. Anaerobe. 17 (5): 226-31.

[19] Zhang L, Liu C, Li D, Zhao Y, Zhang X, Zeng X, Yang Z, Li S. 2013. Antioxidant activity of an exopolysaccharide isolated from Lactobacillus plantarum C88. Int J Biol Macromol. 54 (1): $270-5$.

[20] Li W, Ji J, Chen X, Jiang M, Rui X, Dong M. 2014a. Structural elucidation and antioxidant activities of exopolysaccharides from Lactobacillus helveticus MB2-1. Carbohydr Polym. 15 (2): 351-9.

[21] Wang K, Li W, Rui X, Li T, Chen X, Jiang M, Dong M. 2015b. Chemical modification, characterization and bioactivity of a released exopolysaccharide (r-EPS1) from Lactobacillus plantarum 70810. Glycoconj J. 32 (1-2): 17-27.

[22] Uttara B, Singh AV, Zamboni P, Mahajan RT. 2009 Oxidative stress and neurodegenerative diseases: a review of upstream and downstream antioxidant therapeutic options. Curr Neuropharmacol. 7 (1): 65-74.

[23] Kishk YFM, Al-Sayed HMA. 2007. Free-radical scavenging and antioxidative activities of some polysaccharides in emulsions. LWT-Food Science \& Technology, 40: 270-277. 
[24] Nguyen DTA and Nguyen THK. (2014). Detection on Antioxidant and Cytotoxicity Activities of Exopolysaccharides Isolated in Plant-Originated Lactococcus lactis. Biomedical \& Pharmacology Journal, 7 (1): 33-38.

[25] Guo S, Mao W, Han Y, Zhang X. Structural characteristics and antioxidant activities of the exracellular polysaccharides produced by marine bacterium Edwardisiellatarda. Biores Technol. 2010; 101 (12): 4729-32.

[26] Wang J, Hu S, Nie S, Yu Q and Xie M. 2016. Reviews on Mechanisms of In Vitro Antioxidant Activity of Polysaccharides. Oxidative Medicine and Cellular Longevity, 2016, Article ID 5692852, 13 pages. 